\title{
Effects of mixing intensity on colony size and growth of Microcystis aeruginosa
}

\author{
Zhong Chunni ${ }^{1}$, Yang Guijun ${ }^{2, *}$, Qin Boqiang ${ }^{1}$, Steven W. Wilhelm ${ }^{3}$, Liu Yu ${ }^{2}$, Han Lihua ${ }^{2}$, Rui \\ Zheng $^{2}$, Yang Hongwei ${ }^{1}$ and Zhang Zhou ${ }^{2}$ \\ ${ }^{1}$ Nanjing Institute of Geography and Limnology, Chinese Academy of Sciences, Nanjing 210008, PR China \\ 2 School of Environment and Civil Engineering, Jiangnan University, Wuxi 214122, PR China \\ ${ }^{3}$ Department of Microbiology, The University of Tennessee, Knoxville, TN 37996, USA
}

Received: 19 February 2019; Accepted: 5 May 2019

\begin{abstract}
Mixing is an integral environmental factor that affects lake ecosystems. For the cyanobacterium Microcystis, colony size is important with respects to migration velocity, how cells respond to grazing pressure, light attenuation, nutrient uptake and growth. To understand how mixing shapes colony size and the growth of Microcystis, we measured the effects of different current velocities $(0,0.16,0.32,0.64$, and $1.28 \mathrm{~m} \mathrm{~s}^{-1}$ ) on $M$. aeruginosa in Lake Taihu. After $24 \mathrm{~h}$ of continuous mixing, the mean colony sizes of $M$. aeruginosa in the controls, $0.16,0.32,0.64$, and $1.28 \mathrm{~m} \mathrm{~s}^{-1}$ groups were 23.6, 50.1, 92.9, 67.8, and 37.3 $\mu \mathrm{m}$, respectively. Colony sizes of $M$. aeruginosa in all treatment groups were significantly larger than those in controls. As well, the concentration of soluble extracellular polysaccharide and bound extracellular polysaccharides of $M$. aeruginosa in all treatment groups were significantly higher than those in controls. Except for the highest level of mixing $\left(1.28 \mathrm{~m} \mathrm{~s}^{-1}\right)$, the growth rate of $M$. aeruginosa was significantly higher than that in controls. This study suggested that mixing intensity over short time periods can significantly influence colony size and the growth of $M$. aeruginosa.
\end{abstract}

Keywords: Microcystis / colony size / mixing / EPS / Lake Taihu / growth

\section{Introduction}

The formation of cyanobacterial blooms is one of the most troubling symptoms of eutrophication (Sommaruga et al., 2009). Cyanobacterial blooms alter ecological processes and decrease the economic value of impacted waters. Controlling blooms induced by eutrophication remains a challenge facing water quality and water supply managers globally (Harke et al., 2016).

Many cyanobacterial blooms in eutrophic waters are dominated by the non $\mathrm{N}_{2}$-fixing colonial genus Microcystis. Field investigations have demonstrated that large colonies of Microcystis are a main component of many blooms. In eutrophic Lake Taihu (China), investigations have found that large colonies (colony size $>38-50 \mu \mathrm{m})$ were dominant during Microcystis bloom events (Cao and Yang, 2010; Zhu et al., 2014; Qin et al., 2018), while small colonies (colony size $<50 \mu \mathrm{m}$ ) were dominant in the water column during non-blooming periods (Wu and Kong, 2009; Cao and Yang, 2010). Large Microcystis colonies also dominate during

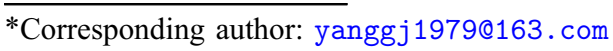

bloom periods in others eutrophic lakes (Sabart et al., 2013). Studies have shown that larger colonies of Microcystis have advantages in upwards floating speed (Xiao et al., 2012), the ability to resisting grazing stress (Oliver and Ganf, 2000), the ability to capture light (Kirk, 1975; Robarts and Zohary, 1984), and nutrient uptake (Shen and Song, 2007). Larger colonies formation by Microcystis better enables cells to access optimal light and nutrient environments by floating on the water surface as a thick "scum" (Reynolds, 2006; Yamamoto et al., 2011; Qin et al., 2018). The above investigations have suggested that Microcystis colony size was of an important facts affecting blooms formation in eutrophic fresh waters.

In fresh waters, Microcystis populations mostly exist as colonies during blooms (Wu and Kong, 2009; Cao and Yang, 2010; Qin et al., 2018). However, in lab, Microcystis colonies usually transform to unicells or paired-cells in growth medium. How Microcystis unicells might transform to colonies remains unclear. Studies have demonstrated many factors that can induce unicell to colony transformation of Microcystis, including biotic and abiotic factors, e.g., zooplankton grazing (Burkert et al., 2001), bacteria (Wang et al., 2016b), microcystins (Sedmak and Eleršek, 2006), high light intensity 
(Xiao, 2011), temperature and phosphorus (Zhu et al., 2016; Duan et al., 2018), and the presence of heavy metals (Bi et al., 2013). Although a lot of research has been conducted, the mechanism of colony formation of Microcystis remains unknown.

Mixing is an integral environmental factor that affects lake ecosystems. Several studies have reported that mixing was an important factor affecting colony size of colonial Microcystis (Regel et al., 2004; Wang et al., 2016c; Xiao et al., 2016; Yang et al., 2017; Li et al., 2018). However, the quantitative effect of mixing on colony size of Microcystis remains unclear. To understand this, we established simulation experiments to measure the effects of different mixing intensity $(0,0.16,0.32$, 0.64 , and $1.28 \mathrm{~m} \mathrm{~s}^{-1}$ ) on $M$. aeruginosa isolated from Lake Taihu. The result of this research shed light on quantitative effect of mixing on colony size and growth of Microcystis and potentially blooms in shallow lakes like Lake Taihu.

\section{Materials and methods}

Single colony of Microcystis aeruginosa, one of the dominant species of Microcystis in Lake Taihu (China), was isolated from lake water in Meiliang Bay (dominated by Microcystis bloom) in Lake Taihu in September 2016 and maintain in BG-11 medium (Rippka et al., 1979). After November 2016, unialgal cultures of $M$. aeruginosa were transferred to modified BG-11 medium (where $\mathrm{TN}=50 \mathrm{mg}$ $\mathrm{L}^{-1}$ and $\mathrm{TP}=2.5 \mathrm{mg} \mathrm{L}^{-1}$ ). Until the beginning of our experiment, the $M$. aeruginosa cultures persisted as a mixture of single-cells, paired-cells and small colonies for a period of five months $\left(\sim 4.83 \times 10^{6}\right.$ cells $\left.\mathrm{mL}^{-1}\right)$. At the beginning of the experiment, $150 \mathrm{~mL}$ inoculums of the exponentially growing $M$. aeruginosa $\left(\sim 4.83 \times 10^{6}\right.$ cells $\left.\mathrm{mL}^{-1}\right)$ were transferred to $500 \mathrm{~mL}$ Erlenmeyer flasks containing $200 \mathrm{~mL}$ of modified BG11 medium. Considering the current velocities of Lake Poyang $\left(0.075-1.34 \mathrm{~m} \mathrm{~s}^{-1}\right)$ (Lai et al., 2015), Lake Chaohu (0.002$0.109 \mathrm{~m} \mathrm{~s}^{-1}$ ) (Wang et al., 2016a), and Lake Taihu (0.005$0.077 \mathrm{~m} \mathrm{~s}^{-1}$ ) (Zhou et al., 2016), different mixing intensities were designed as following: 0, 50, 100, 200, and $400 \mathrm{rpm}$, which approximate current velocities of $0,0.16,0.32,0.64$, and $1.28 \mathrm{~m} \mathrm{~s}^{-1}$ (Camacho et al., 2007; Rodríguez et al., 2009), respectively. For treatments, continuous mixing was maintained for $24 \mathrm{~h}$ while the $0 \mathrm{rpm}$ groups were considered as the controls. All treatments were maintained in triplicate. Next, treatment groups were put into $500 \mathrm{~mL}$ flasks then put on four shaker incubators $(50,100,200$ and $400 \mathrm{rpm})$ for $24 \mathrm{~h}$ at $25^{\circ} \mathrm{C}$ under dark to simulate the effect of the mixing induce by windwave on $M$. aeruginosa. Mixing was generated on four horizontally oscillating shaking incubators. After shaking treatments, cultures were maintained in a "quiescent state" (i.e., no shaking). Controls were kept quiescent during the entire experimental period. Finally, after continuing mixing for $24 \mathrm{~h}$, all groups were put in incubator at $25^{\circ} \mathrm{C}$ under cool white fluorescent lights at an intensity of $40.5 \mathrm{~mol} \mathrm{~m}^{-2} \mathrm{~s}^{-1}$ with a light-dark period of $12: 12 \mathrm{~h}$. The total concentration of nitrogen and phosphorus in all groups nutrient were $\mathrm{TN}=$ $50 \mathrm{mg} \mathrm{L}^{-1}$ and $\mathrm{TP}=2.5 \mathrm{mg} \mathrm{L}^{-1}$ at the start of the shaking.

Samples were collected at $0,1,3,5,7,9$, and 11 th days into this experiment to measure EPS (extracellular polysaccharide), colony size and abundance of M. aeruginosa. The content of soluble extracellular polysaccharide (sEPS) and bound extracellular polysaccharide (bEPS) were quantified spectrophotometrically by the anthrone method (Herbert et al., 1971) using glucose as standard. Samples of $M$. aeruginosa $(5 \mathrm{~mL})$ were preserved with Lugol's iodine solution: these samples were concentrated to $1 \mathrm{~mL}$ after $5 \mathrm{~mL}$ of $M$. aeruginosa settled for 48 h.M. aeruginosa colonies in the concentrated samples were measured (400x magnification) with a Nikon E200 microscope and QCapture Pro software (QImaging, Surrey BC, Canada). To determine mean colony size, at least 100 colonies of $M$. aeruginosa were measured. The abundance of $M$. aeruginosa was for at least 100 units for unicell and paired-cells, at least 100 colonies for $3-10$ cell colony ${ }^{-1}$ and $10-100$ cells colony ${ }^{-1}$ and 100 colonies for $>100$ cells colony $^{-1}$. The concentrations of Chla were determined by spectrophotometry.

\section{Statistical analyses}

One-way analysis of variance (ANOVA) was used to test the differences in EPS, abundance, and colony size of $M$. aeruginosa between treatments and controls. All analyses were made using the SPSS19.0 computer programs.

\section{Results}

\subsection{The colony size of $M$. aeruginosa}

In this experiment, the mean colony sizes of $M$. aeruginosa in controls, $0.16,0.32,0.64$, and $1.28 \mathrm{~m} \mathrm{~s}^{-1}$ groups were 23.2 $( \pm 1.8), \quad 35.7( \pm 1.2), \quad 51.6( \pm 2.6), 40.8( \pm 4.3)$, and 25.7 $( \pm 2.4) \mu \mathrm{m}$, respectively (Fig. 1a). ANOVA showed that the mean colony sizes of $M$. aeruginosa in $0.16,0.32,0.64 \mathrm{~m} \mathrm{~s}^{-1}$ groups were significantly larger than those in controls $(P<0.01)$, but no significant difference between mean colony size of $M$. aeruginosa in controls and the $1.28 \mathrm{~m} \mathrm{~s}^{-1}$ groups was found $(P>0.05)$. In the first day in this experiment, the colony size of $M$. aeruginosa in $0.16,0.32,0.64$, and $1.28 \mathrm{~m} \mathrm{~s}^{-1}$ groups increased after continuing mixing for $24 \mathrm{~h}$. The colony size of $M$. aeruginosa in controls, $0.16,0.32,0.64$, and $1.28 \mathrm{~m} \mathrm{~s}^{-1}$ groups was $23.6( \pm 1.8), 50.1( \pm 8.6), 92.9$ $( \pm 4.8), 67.8( \pm 10.9)$, and $37.3( \pm 3.9) \mu \mathrm{m}$, respectively (Figs. $1 \mathrm{~b}$ and 2). An ANOVA showed that the colony sizes of $M$. aeruginosa in all treatment groups were significantly larger than that in control $(P<0.05)$ in the first day in this experiment. The colony size of $M$. aeruginosa in all treatment groups gradually decreases with the time, while the colony size of $M$. aeruginosa in control keep steady (around $23 \mu \mathrm{m}$ ) (Fig. 1b). At the 11th day of the experiment, the colony size of $M$. aeruginosa in controls, $0.16,0.32,0.64$, and $1.28 \mathrm{~m} \mathrm{~s}^{-1}$ groups was $23.0( \pm 3.7), 28.2( \pm 4.7), 33.9( \pm 3.3), 25.2( \pm 1.6)$, and $22.1( \pm 2.1) \mu \mathrm{m}$, respective (Fig. 1b).

\subsection{The EPS of $M$. aeruginosa}

EPS (extracellular polysaccharides) have been shown to be important in colony formation of Microcystis (Yang et al., 2008). In this study, there was no significant difference between the mean value of sEPS (soluble extracellular 

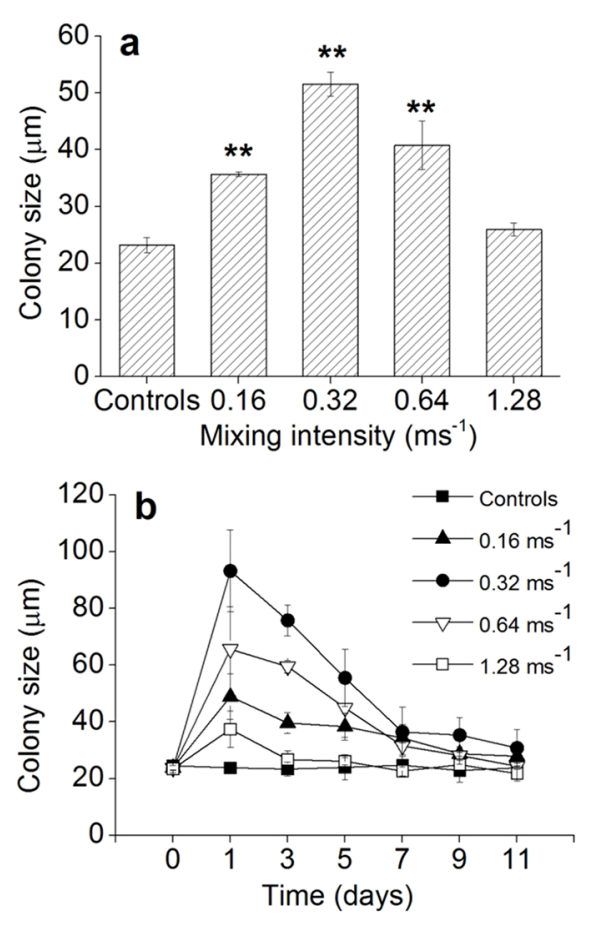

Fig. 1. Mean colony size and colony size variations of $M$. aeruginosa in controls, $0.16,0.32,0.64$, and $1.28 \mathrm{~m} \mathrm{~s}^{-1}$ groups in this experiment. Error bars represent $\pm \mathrm{SD}\left({ }^{*} P<0.05,{ }^{* *} P<0.01, n=3\right)$. a $=$ mean colony size of $M$. aeruginos $\mathrm{a} \mathrm{b}=$ colony size variations of $M$. aeruginosa with time.

polysaccharides), and bEPS (bound extracellular polysaccharides) of $M$. aeruginosa in controls and that in $0.16,0.32,0.64$, and $1.28 \mathrm{~m} \mathrm{~s}^{-1}$ groups during this experiment $(P>0.05)$. However, on the first day after continuing mixing for $24 \mathrm{~h}$, the concentration of SEPS for $M$. aeruginosa in $0.16 \mathrm{~m} \mathrm{~s}^{-1}$ $\left(1.70 \mathrm{pg} \mathrm{cell}^{-1}\right), \quad 0.32 \mathrm{~m} \mathrm{~s}^{-1}\left(1.78 \mathrm{pg} \mathrm{cell}^{-1}\right), \quad 0.64 \mathrm{~m} \mathrm{~s}^{-1}$ $\left(1.70 \mathrm{pg} \mathrm{cell}^{-1}\right)$, and $1.28 \mathrm{~m} \mathrm{~s}^{-1}\left(1.70 \mathrm{pg} \mathrm{cell}^{-1}\right)$ were significantly higher than that in controls $\left(1.44 \mathrm{pg} \mathrm{cell}^{-1}\right)(P<0.01)$ (Fig. 3). Also, the concentration value of bEPS of $M$. aeruginosa in $0.16 \mathrm{~m} \mathrm{~s}^{-1}\left(0.38 \mathrm{pg} \mathrm{cell}^{-1}\right), 0.32 \mathrm{~m}^{-1}(0.45 \mathrm{pg}$ cell $\left.^{-1}\right), 0.64 \mathrm{~m} \mathrm{~s}^{-1}\left(0.39 \mathrm{pg} \mathrm{cell}^{-1}\right)$, and $1.28 \mathrm{~m} \mathrm{~s}^{-1}(0.36 \mathrm{pg}$ cell $^{-1}$ ) groups were significantly higher than that in controls $\left(0.26 \mathrm{pg} \mathrm{cell}^{-1}\right)(P<0.05)$. The concentration of sEPS and bEPS for $M$. aeruginosa in all groups gradually decreased with the time after the first day in this experiment (Fig. 3).

\subsection{The abundance and growth of $M$. aeruginosa}

The mean abundance of $M$. aeruginosa in controls, 0.16 , $0.32,0.64$, and $1.28 \mathrm{~m} \mathrm{~s}^{-1}$ groups was 4.05, 4.79, 5.17, 4.48, and $4.30 \times 10^{6}$ cells mL $\mathrm{mL}^{-1}$ (Fig. 4a), respectively. The mean abundance of $M$. aeruginosa in $0.16,0.32$, and $0.64 \mathrm{~m} \mathrm{~s}^{-1}$ groups was significantly higher than those in controls and in the $1.28 \mathrm{~m} \mathrm{~s}^{-1}$ groups $(P<0.01)$ (Fig. 4a). The growth rates of M. aeruginosa in controls, $0.16,0.32,0.64$, and $1.28 \mathrm{~m} \mathrm{~s}^{-1}$ groups was $0.227( \pm 0.006), 0.271( \pm 0.007), 0.298( \pm 0.006)$, $0.240( \pm 0.007)$, and $0.220 / \mathrm{d}( \pm 0.007)$ (Fig. 5b), respectively. The growth rates of $M$. aeruginosa in $0.16,0.32,0.64 \mathrm{~m} \mathrm{~s}^{-1}$ groups were significantly higher than that in controls and in
$1.28 \mathrm{~m} \mathrm{~s}^{-1}$ groups $(P<0.05)$, while no significantly different between the growth rates of $M$. aeruginosa in $1.28 \mathrm{~m} \mathrm{~s}^{-1}$ groups and that in controls $(P>0.05)$. The variations of abundance and Chla of $M$. aeruginosa in this study were showed in Figure 5. The abundance of $M$. aeruginosa in $0.32 \mathrm{~m} \mathrm{~s}^{-1}$ groups $\left(8.87 \times 10^{6}\right.$ cells $\left.\mathrm{mL}^{-1}\right)$ was the highest among all groups at the end of experiment. Similar were found in Chla of M. aeruginosa in $0.32 \mathrm{~m} \mathrm{~s}^{-1}$ groups $\left(2212 \mu \mathrm{g} \mathrm{L}^{-1}\right)$ (Fig. 5).

Before mixing, no colonies with $>100$ cells of $M$. aeruginosa were found in any treatment groups or the controls (Tab. 1). After mixing for $24 \mathrm{~h}$, the proportion of cells within $>100$ cell colonies relative to total abundance of $M$. aeruginosa increased from 0 to 9.68 in $0.16 \mathrm{~m} \mathrm{~s}^{-1}$ groups, from 0 to 32.13 in $0.32 \mathrm{~m} \mathrm{~s}^{-1}$ groups, from 0 to 28.29 in $0.64 \mathrm{~m} \mathrm{~s}^{-1}$ groups, and from 0 to $15.64 \%$ in $1.28 \mathrm{~m} \mathrm{~s}^{-1}$ groups on the first day, respectively. However, no colonies with $>100$ cells of M. aeruginosa were found in control groups on the first day. In contrast, on the first day, the proportion of cells in 10-100 cell colonies of $M$. aeruginosa significantly decreased in all treatment groups (Tab. 1) after mixing, e.g., in the $0.32 \mathrm{~m} \mathrm{~s}^{-1}$ groups, the cell abundance proportion of $10-100$ cells colony to total abundance of $M$. aeruginosa decreased from $57.00 \%$ to $30.13 \%$ (Tab. 1). This suggested that $>100$ cell colonies of $M$. aeruginosa may have come from the aggregation of $3-100$ cells colony by mixing, especially the $10-100$ cells colony.

\section{Discussion}

In this study, we found that mixing intensities $(0.16$ $0.64 \mathrm{~m} \mathrm{~s}^{-1}$ ) favor increased colony sizes for M. aeruginosa. Wang et al. (2016c) reported that colony size of Microcystis significantly increased after mixing driven by Typhoon Soulik in Lake Taihu. Yang et al. (2017) found that simulating mixing (24 h) significantly enlarged the colony sized of Microcystis in Lake Taihu. However, O'Brien et al. (2004) reported that Microcystis colonies collected from field broke up into smaller colonies $(<200 \mu \mathrm{m})$ after mixing. Xiao's (2016) study showed that no colonies conformation was found after mixing. Li et al. (2018) reported that three species of Microcystis colonies collected from Lake Taihu broke up into smaller colonies after mixing. Overall these previous observations have resulted in conflicting results concerning the effects of mixing on colony formation by Microcystis.

One important variable to be considered is the starting conditions of Microcystis for each of these studies. In the current experiment, the mean colony size of $M$. aeruginosa was $23.6 \mu \mathrm{m}$ at the onset of experiment, while it was above $200 \mu \mathrm{m}$ in O'Brien's (2004) study. In Xiao's (2016) study, the Microcysits was only single-cells, while those were a mixture of single-cells, paired-cells and small colonies of $M$. aeruginosa in this study. Similarly in our study the mixing used was continuous over $24 \mathrm{~h}$, while it was $30 \mathrm{~min}$ in Li's (2018) study. In total the above studies showed that whether the colonies of Microcystis aggregate or disaggregate after mixing may depend on the mixing intensity, the mixing time and colony size of Microcystis.

EPS are mainly found in mucilage or the cell's sheath, and it can affect the "stickiness" of the cell surface, contributing to 


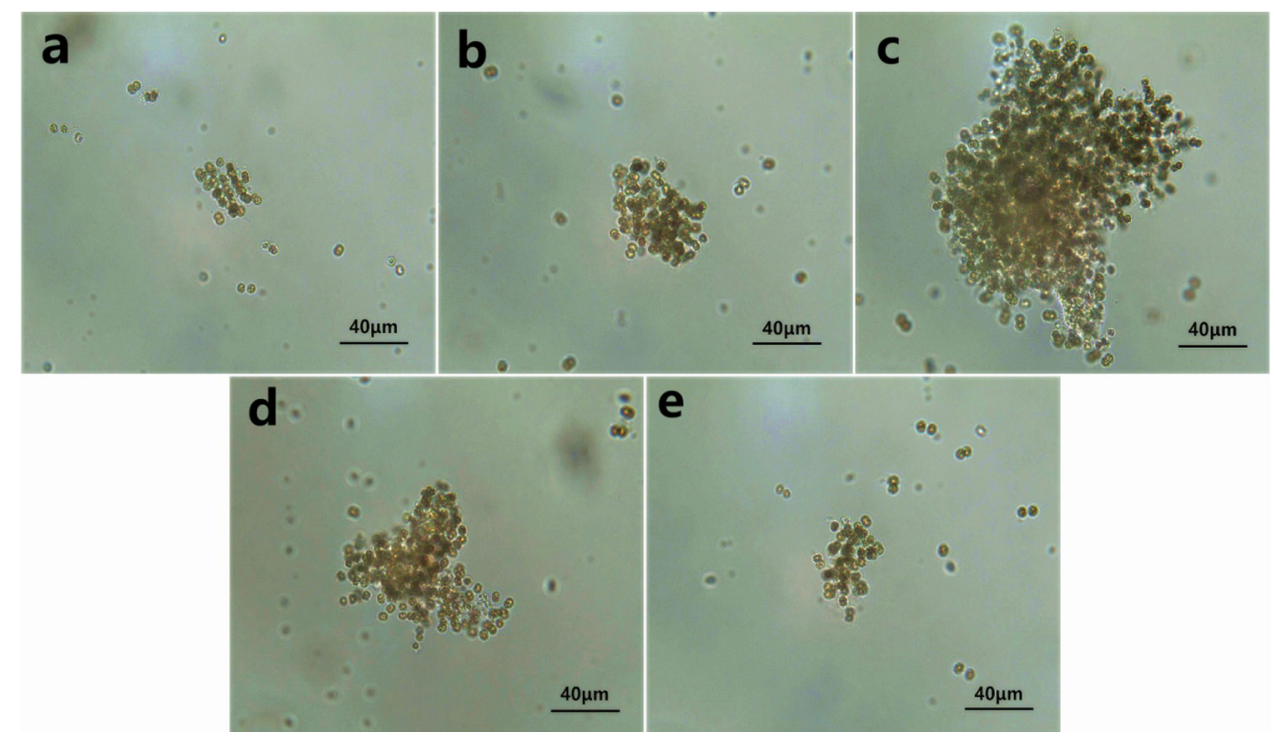

Fig. 2. Images of typical M. aeruginosa cells in controls, $0.16,0.32,0.64$, and $1.28 \mathrm{~m} \mathrm{~s}^{-1}$ groups after continuing mixing for $24 \mathrm{~h}$ in the first day in this experiment. $a=$ controls; $b=0.16 \mathrm{~m} \mathrm{~s}^{-1} ; \mathrm{c}=0.32 \mathrm{~m} \mathrm{~s}^{-1} ; \mathrm{d}=0.64 \mathrm{~m} \mathrm{~s}^{-1} ; \mathrm{e}=1.28 \mathrm{~m} \mathrm{~s}^{-1}$.
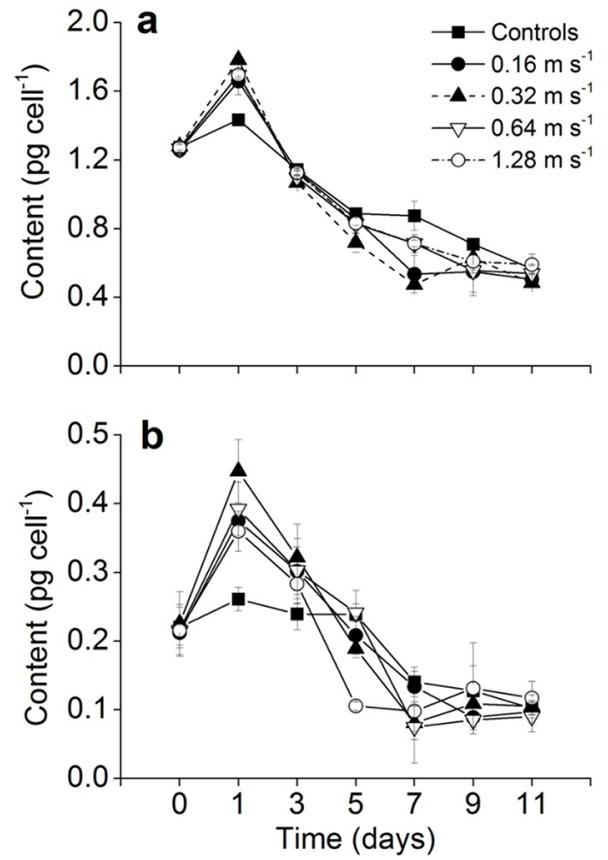

Fig. 3. Extracellular polysaccharides of $M$. aeruginosa in controls, $0.16,0.32,0.64$, and $1.28 \mathrm{~m} \mathrm{~s}^{-1}$ groups in this experiment. $\mathrm{sEPS}=$ soluble extracellular polysaccharides; bEPS = bound extracellular polysaccharides; $\mathrm{a}=\mathrm{sEPS}$ of $M$. aeruginosa; $\mathrm{b}=\mathrm{bEPS}$ of $M$. aeruginosa.

colony formation in Microcystis (Yang et al., 2008; Li et al., 2013; Zhu et al., 2014). Research has shown that the concentration of EPS in Microcystis colonies was significantly higher than in single cells (Li et al., 2013). Small colonies of Microcystis may come from the division of mother cell and adhesion via EPS (Kessel and Eloff, 1975). It is thought that sEPS (soluble extracellular polysaccharides) may increase cell
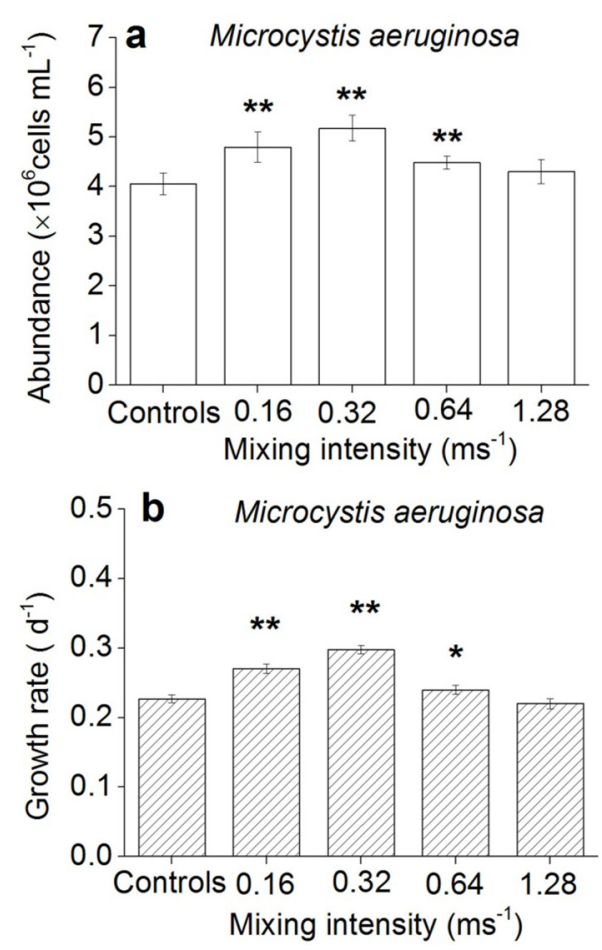

Fig. 4. Mean abundance and growth rates of M. aeruginosa in controls, $0.16,0.32,0.64$, and $1.28 \mathrm{~m} \mathrm{~s}^{-1}$ groups in this experiment. Error bars represent $\pm \mathrm{SD}\left({ }^{*} P<0.05, * * P<0.01, n=3\right)$. a = mean abundance of $M$. aeruginosa; $\mathrm{b}=$ growth rates of $M$. aeruginosa.

adhesiveness, while the bEPS (bound extracellular polysaccharides) may prevent daughter cells from separating after cell division (Li et al., 2013). In this study, the concentrations of bEPS and sEPS of $M$. aeruginosa in $0.16,0.32,0.64$, and $1.28 \mathrm{~m} \mathrm{~s}^{-1}$ were significantly higher than that in controls after 

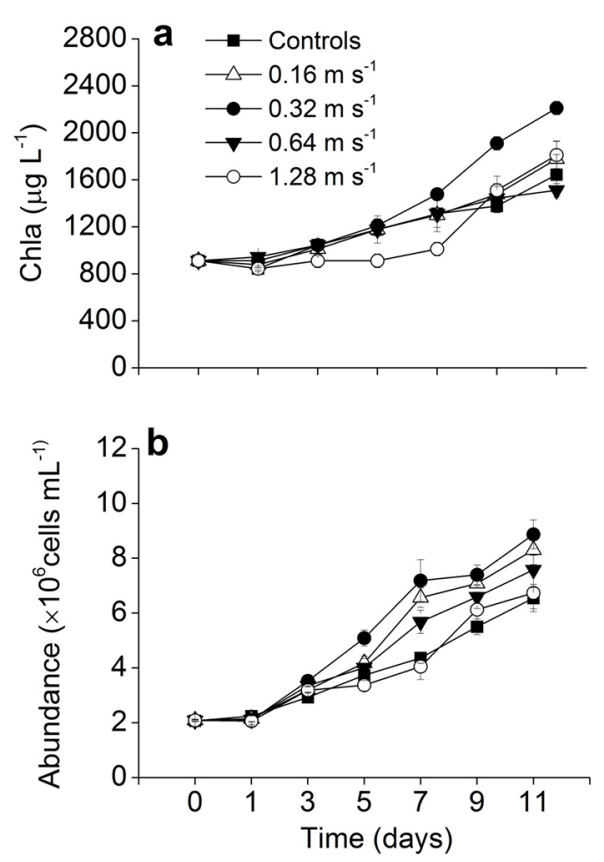

Fig. 5. Variation of abundance and Chla of $M$. aeruginosa in controls, $0.16,0.32,0.64$, and $1.28 \mathrm{~m} \mathrm{~s}^{-1}$ groups in this experiment. $\mathrm{a}=$ Chla of $M$. aeruginosa $; \mathrm{b}=$ abundance of $M$. aeruginosa.

continuing mixing for $24 \mathrm{~h}(P<0.05)$. The increased bEPS and sEPS after mixing may explain why colony size of $M$. aeruginosa enlarged in all treatment in this study, especially in $0.32 \mathrm{~m} \mathrm{~s}^{-1}$ groups.

Many studies have shown that stress conditions can lead to EPS production and releasing by Microcystis spp., including grazing of plankton (Yang et al., 2008), high concentration of calcium (Wang et al., 2011) and microcystin-RR (Gan et al., 2012). Gan et al. (2012) found that microcystin-RR induced EPS in the culture medium and up regulated genes related to polysaccharide biosynthesis, but had no effect on the cell growth rate. Li et al. (2007) founded that allelopathy material eathyl-2-methyl acetoacetate (EMA) produced by reed could raise the respiration rate of $M$. aeruginosa, causing the $\mathrm{CO}_{2}$ concentration raising in its culture flask, lowering the photosynthesis action rate of $M$. aeruginosa. In this study, mixing is one of stress conditions, so EPS content in the mixing treated groups was much higher than that of the control after mixing for $24 \mathrm{~h}$ in the dark and no significant difference was observed in both cell density and Chla. Also, we infer that respiration rate in all treated groups would raise to satisfy the energy requirement of EPS production and releasing of Microcystis spp. in the mixing treated groups.

The abundance and growth rates of $M$. aeruginosa in 0.16 , 0.32 , and $0.64 \mathrm{~m} \mathrm{~s}^{-1}$ groups were significantly higher than that in controls groups and in $1.28 \mathrm{~m} \mathrm{~s}^{-1}$ groups $(P<0.05)$, while the abundance and growth rates were not significantly different between the $1.28 \mathrm{~m} \mathrm{~s}^{-1}$ groups and controls $(P>0.05)$. Regel et al. (2004) demonstrated that low mixing intensities had no effect on the growth rate of $M$. aeruginosa, but high mixing intensity decreased growth rates. Yan et al. (2008) reported that certain mixing intensities stimulated the growth of $M$. aeruginosa, but high mixing intensities inhibited the growth of
$M$. aeruginosa under low nutrient availability and all mixing intensities had no significant effect on the growth of $M$. aeruginosa under eutrophic nutrient. Jiang et al. (2012) found that low mixing intensity stimulated the growth of $M$. aeruginosa while high mixing intensity inhibited growth. Turbulence is reported to decrease the diffusive boundary layer around cells, theoretically increasing nutrient diffusion to cells (Lazier and Mann, 1989) and potentially increasing metabolic activity. Regel et al. (2004) found that low mixing intensities increased the esterase activity and cell viability of $M$. aeruginosa, but these were decreased at high mixing intensities. In this study, the values of $\mathrm{ETR}_{\max }$ (the potential maximum photosynthetic rate) and $\mathrm{I}_{\mathrm{k}}$ (half saturation light intensity) of $M$. aeruginosa in $0.16,0.32$, and $0.64 \mathrm{~m} \mathrm{~s}^{-1}$ groups were significantly higher than those in controls and $1.28 \mathrm{~m} \mathrm{~s}^{-1}$ groups $(P<0.01)$ in the 3 rd day after mixing (Fig. S1). This may explain why growth rates of $M$. aeruginosa in $0.16,0.32,0.64 \mathrm{~m} \mathrm{~s}^{-1}$ groups were significantly higher than that in controls groups and in $1.28 \mathrm{~m} \mathrm{~s}^{-1}$ groups. Moreover, the values of MDA and SOD activities of $M$. aeruginosa in $1.28 \mathrm{~m} \mathrm{~s}^{-1}$ groups were significantly higher than those in controls and the $0.16,0.32$, and $0.64 \mathrm{~m} \mathrm{~s}^{-1}$ groups after mixing (Fig. S2). This information suggested that the hurt by high intensity mixing $\left(1.28 \mathrm{~m} \mathrm{~s}^{-1}\right)$ on $M$. aeruginosa maybe lead to the lower growth of $M$. aeruginosa.

Taihu Lake, the third largest freshwater lake in China is shallow and hypereutrophic. Microcystis blooms have occurred from May to October every year since the 1950s and have been larger and more severe since the 1980s (Qin, 2008). M. aeruginosa has been one of the dominant species of Microcystis in Lake Taihu (Yang et al., 2009). The mixing induced by wind-wave action in Lake Taihu is frequent due to the lakes shallow depth, large surface area and large fetch. This mixing leads to reduced transparency and nutrient resuspension into the water column from the sediments (Qin, 2008). Moreover, the mixing can increase the colony size of Microcystis. During the Typhoon Soulik (July 12-13, 2013), the mean current velocities was $0.0361 \mathrm{~m} \mathrm{~s}^{-1}$ (range $0.0063-0.1031 \mathrm{~m} \mathrm{~s}^{-1}$ ) in Lake Taihu (Wu et al., 2015). And the mean colony size of Microcystis in Lake Taihu significantly increased from $32.8 \mu \mathrm{m}$ in pre-typhoon period to $69.4 \mu \mathrm{m}$ in post-typhoon period within $48 \mathrm{~h}$ (Qin et al., 2018). The increasing of colony size of $M$. aeruginosa by mixing favors upward movement of cells, enhancing exposure to light and subsequently growth and biomass accumulation (Cao and Yang, 2010; Yamamoto et al., 2011; Qin et al., 2018). This may explain why $M$. aeruginosa consistently becomes the dominant species of phytoplankton in Lake Taihu.

\section{Supplementary Material}

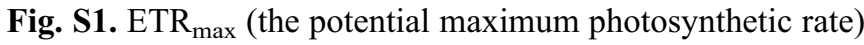
and $\mathrm{I}_{\mathrm{k}}$ (half saturation light intensity) of $M$. aeruginosa in controls, $0.16,0.32,0.64$, and $1.28 \mathrm{~m} \mathrm{~s}^{-1}$ groups in this experiment. Error bars represent $\pm \mathrm{SD}(* P<0.05$, $* * P<0.01$, $n=3) . \mathrm{a}=\mathrm{I}_{\mathrm{k}}, \mathrm{b}=\mathrm{ETR}_{\max }$.

Fig. S2. MDA and SOD activity of $M$. aeruginosa in controls, $0.16,0.32,0.64$, and $1.28 \mathrm{~m} \mathrm{~s}^{-1}$ groups in this experiment. Error bars represent $\pm \mathrm{SD}(* P<0.05, * * P<0.01, n=3)$. $\mathrm{a}=\mathrm{MDA}, \mathrm{b}=\mathrm{SOD}$. 
Table 1. The abundance proportion of different units to total abundance $M$. aeruginosa before and after continuing mixing for $24 \mathrm{~h}$.

\begin{tabular}{|c|c|c|c|c|c|c|}
\hline Mix intensity $\left(\mathrm{m} \mathrm{s}^{-1}\right)$ & Time (day) & $\begin{array}{l}\text { Unicell } \\
(\% \text { total cells })\end{array}$ & $\begin{array}{l}\text { Two-cells } \\
\text { (\% total cells) }\end{array}$ & $\begin{array}{l}3-10 \text { cells } \\
(\% \text { total cells })\end{array}$ & $\begin{array}{l}10-100 \text { cells } \\
(\% \text { total cells })\end{array}$ & $\begin{array}{l}>100 \text { cells } \\
(\% \text { total cells })\end{array}$ \\
\hline Controls & 0 & $7.74 \pm 0.19$ & $11.29 \pm 0.19$ & $24.26 \pm 0.93$ & $56.71 \pm 0.80$ & $0.00 \%$ \\
\hline \multirow{2}{*}{0.16} & 0 & $8.23 \pm 0.22$ & $11.12 \pm 0.17$ & $23.90 \pm 0.24$ & $56.75 \pm 0.69$ & $0.00 \%$ \\
\hline & 1 & $9.02 \pm 0.06$ & $11.21 \pm 0.40$ & $20.67 \pm 0.09$ & $49.42 \pm 0.70$ & $9.68 \pm 0.38$ \\
\hline 0.32 & 0 & $8.30 \pm 0.18$ & $11.14 \pm 0.06$ & $23.56 \pm 0.12$ & $57.00 \pm 0.17$ & $0.00 \%$ \\
\hline \multirow{2}{*}{0.64} & 0 & $8.24 \pm 0.24$ & $11.10 \pm 0.18$ & $24.02 \pm 0.46$ & $56.63 \pm 0.59$ & $0.00 \%$ \\
\hline & 1 & $8.49 \pm 0.06$ & $10.74 \pm 0.26$ & $17.33 \pm 0.15$ & $35.14 \pm 0.50$ & $28.29 \pm 0.06$ \\
\hline \multirow{2}{*}{1.28} & 0 & $8.27 \pm 0.18$ & $11.14 \pm 0.26$ & $23.48 \pm 0.26$ & $57.10 \pm 0.73$ & $0.00 \%$ \\
\hline & 1 & $11.62 \pm 0.18$ & $13.05 \pm 0.13$ & $28.48 \pm 0.64$ & $31.21 \pm 0.06$ & $15.64 \pm 0.33$ \\
\hline
\end{tabular}

The Supplementary Material is available at https://www. limnology-journal.org/10.1051/limn/2019011/olm.

Acknowledgments. This study was funded by Water Pollution Control and Management Project (Grant \#2012ZX07503-002), a Natural Scientific Foundation of China (Grant \#41230744) and a National Science Foundation (USA) grant (DEB-1240870).

Conflicts of interest. The authors declare that they have no conflicts of interest in relation to this article.

\section{References}

Bi XD, Zhang SL, Dai W, et al. 2013. Effects of lead (II) on the extracellular polysaccharide (EPS) production and colony formation of cultured Microcystis aeruginosa. Water Sci Technol 67(4): 803-809.

Burkert PH, Drakare S, Blomqvist P. 2001. Effects of the mixotrophic flagellate Ochromonas sp. on colony formation in Microcystis aeruginosa. Aquat Ecol 35: 11-17.

Camacho FG, Rodríguez JJG, Mirón AS, et al. 2007. Determination of shear stress thresholds in toxic dinoflagellates cultured in shaken flasks: Implications in bioprocess engineering. Process Biochem 42(11): 1506-1515.

Cao HS, Yang Z. 2010. Variation in colony size of Microcystis aeruginosa in a eutrophic lake during recruitment and bloom formation. J Freshw Ecol 25(3): 331-335.

Duan ZP, Tan X, Parajuli K, et al. 2018. Colony formation in two Microcystis morphotypes: Effects of temperature and nutrient availability. Harmful Algae 72: 14-24.

Gan N, Xiao Y, Zhu L, et al. 2012. The role of microcystins in maintaining colonies of bloom-forming Microcystis spp. Environ Microbiol 14(3): 730-742.

Harke MJ, Steffen MM, Gobler CJ, et al. 2016. A review of the global ecology, genomics, and biogeography of the toxic cyanobacterium, Microcystis spp. Harmful Algae 54: 4-20.

Herbert D, Phipps PJ, Strange RE. 1971. Chemical analysis of microbial cells. London, UK: Academic Press, 209 p.

Jiang LY, Jiang C, Zhou W, He YL. 2012. Growth of Microcystis aeruginosa under different disturbance. Environ Chem 31(2): 216-220 (in Chinese).

Kessel M, Eloff JN. 1975. The ultrastructure and development of the colonial sheath of Microcystis marginata. Arch Microbiol 106: 209-214.
Kirk JTOA. 1975. Theoretical analysis of the contribution of algal cells to the attenuation of light within natural waters. II. Spherical cells. New Phytol 75: 21-36.

Lai G, Wang P, Huang X, et al. 2015. A simulation research of impacts of the Lake Poyang hydraulic project on hydrology and hydrodynamics. J Lake Sci 27(1): 128-140.

Lazier JRN, Mann KH. 1989. Turbulence and the diffusive layers around small organisms. Deep-Sea Res 36: 1721-1733.

Li F, Hu H, Chong Y, et al. 2007. Influence of EMA isolated from Phragmites communis on physiological characters of Microcystis aeruginosa. China Environ Sci 27(3): 377-381.

Li M, Zhu W, Gao L, Lu L. 2013. Changes in extracellular polysaccharide content and morphology of Microcystis aeruginosa at different specific growth rates. J Appl Phycol 25(4): 1023-1030.

Li M, Xiao M, Zhang P, Hamilton DP. 2018. Morphospeciesdependent disaggregation of colonies of the cyanobacterium Microcystis under high turbulent mixing. Water Res 141: 340-348.

O'Brien KR, Meyer DL, Waite AW, et al. 2004. Disaggregation of Microcystis aeruginosa colonies under turbulent mixing: Laboratory experiments in a grid-stirred tank. Hydrobiologia 519: 143-152.

Oliver RL, Ganf GG. 2000. Freshwater blooms. Dordrecht: Kluwer Academic Publishers, pp. 149-194.

Qin BQ. 2008. Lake Taihu, China-dynamics and environmental change. Berlin: Springer Press.

Qin BQ, Yang GJ, Ma JR, et al. 2018. Spatiotemporal changes of cyanobacterial bloom in large shallow eutrophic Lake Taihu, China. Front Microbiol 9: 451.

Regel RH, Brookes JD, Ganf GG, Griffiths RW. 2004. The influence of experimentally generated turbulence on the Mash01 unicellular Microcystis aeruginosa strain. Hydrobiologia 517: 107-120.

Reynolds CS. 2006. The ecology of phytoplankton. Cambridge: Cambridge University Press.

Rippka R, Deruelles J, Waterbury J, Herdman M, Stanier R. 1979. Generic assignments, strain histories and properties of pure cultures of cyanobacteria. J Gen Microbiol 111: 1-61.

Robarts RD, Zohary T. 1984. Microcystis aeruginosa and underwater light attenuation in a hypertrophic lake (Hartbeesport Dam, South Africa). J Ecol 72: 1001-1017.

Rodríguez JJG, Mirón AS, Camacho FG, et al. 2009. Causes of shear sensitivity of the toxic dinoflagellate. Protoceratium reticulatum. Biotechnol Progr 25(3): 792-800.

Sabart M, Misson B, Descroix A, et al. 2013. The importance of small colonies in sustaining Microcystis population exposed to mixing conditions: An exploration through colony size, genotypic 
composition and toxic potential. Environ Microbiol Rep 5(5): 747-756.

Sedmak B, Eleršek T. 2006. Microcystins induce morphological and physiological changes in selected representative phytoplanktons. Microb Ecol 51: 508-515.

Shen H, Song L. 2007. Comparative studies on physiological responses to phosphorus in two phenotypes of bloom forming Microcystis. Hydrobiologyia 592(1): 475-486.

Sommaruga R, Chen YW, Liu ZW. 2009. Multiple strategies of bloom-forming Microcystis to minimize damage by solar ultraviolet radiation in surface waters. Microb Ecol 57: 667-674.

Wang YW, Zhao J, Li JH, et al. 2011. Effects of calcium levels on colonial aggregation and buoyancy of Microcystis aeruginosa. Curr Microbiol 62(2): 679-683.

Wang Y, Wang L, Hua Z, et al. 2016a. The relationships of velocity, dissolved oxygen with $\mathrm{Fe}^{2+}, \mathrm{S}^{2-}$ in black bloom region on Nanfei River estuary of Lake Chaohu. J Lake Sci 28(4): 710-717.

Wang WJ, Shen H, Shi PL, Chen J, Ni LY, Xie P. 2016b. Experimental evidence for the role of heterotrophic bacteria in the formation of Microcystis colonies. J Appl Phycol 28: 1111-1123.

Wang YB, Yang GJ, Qin BQ, et al. 2016c. Effect of typhoon on the size of Microcystis colonies in Lake Taihu. Chin J Environ Eng 10 (7): 3961-3966 (in Chinese).

Wu XD, Kong FX. 2009. Effects of light and wind speed on the vertical distribution of Microcystis aeruginosa colonies of different sizes during a summer bloom. Int Rev Hydrobiol 94 (3): 258-266.

Wu T, Wang Z, Niu C, et al. 2015. The effect of intense hydrodynamic disturbance on chromophoric dissolved organic matter in a shallow eutrophic lake. J Freshw Ecol 30(1): 143-156.

Xiao Y. 2011. Responses and underlying mechanism of colonial Microcystis to light intensity and microcystins [D]. Thesis for Doctor of Science, Institute of Hydrobiology, Chinese Academy of Sciences, Wuhan (in Chinese).
Xiao Y, Gan NQ, Liu J, Zheng LL, Song LR. 2012. Heterogeneity of buoyancy in response to light between two buoyant types of cyanobacterium Microcystis. Hydrobiologia 679: 297-311.

Xiao Y, Li Z, Li C, Zhang Z, Guo J. 2016. Effect of small-scale turbulence on the physiology and morphology of two bloomforming cyanobacteria. PloS ONE 11(12): e0168925.

Yamamoto Y, Shiah FK., Chen YL. 2011. Importance of large colony formation in bloom-forming cyanobacteria to dominate in eutrophic ponds. Ann Limnol Int J Limnol 47: 167-173.

Yan RR, Pang Y, Chen XF, Zhao W, Ma J. 2008. Effect of disturbance on growth of Microcystis aeruginosa in different nutrient levels. Environ Sci 29(10): 2749-2753 (in Chinese).

Yang Z, Kong F, Shi X, Zhang M, Xing P, Cao H. 2008. Changes in the morphology and polysaccharide content of Microcystis aeruginosa (Cyanobacteria) during flagellate grazing. J Phycol 44(3): 716-720.

Yang GJ, Qin BQ, Gao G, et al. 2009. Effect of Ceriodaphnia cornuta in colony formation of Microcystis in Lake Taihu. J Lake Sci 21(4): 495-501 (in Chinese).

Yang GJ, Zhong CN, Qin BQ, et al. 2017. Effect of in situ simulative mixing on colony size of Microcystis in Lake Taihu. J Lake Sci 29(2): 363-368 (in Chinese).

Zhu W, Li M, Luo Y, et al. 2014. Vertical distribution of Microcystis colony size in Lake Taihu: Its role in algal blooms. J Great Lakes Res 40(4): 949-955.

Zhu W, Zhou X, Chen H, Gao L, Xiao M, Li M. 2016. High nutrient concentration and temperature alleviated formation of large colonies of Microcystis: Evidence from field investigations and laboratory experiments. Water Res 101: 167-175.

Zhou J, Han XX, Qin BQ, Céline C, Yang GJ. 2016. Response of zooplankton community to turbulence in large, shallow Lake Taihu: A mesocosm experiment. Fund Appl Limnol 187(4): 315-324.

Cite this article as: Chunni Z, Guijun Y, Boqiang Q, Wilhelm SW, Yu L, Lihua H, Zheng R, Hongwei Y, Zhou Z. 2019. Effects of mixing intensity on colony size and growth of Microcystis aeruginosa. Ann. Limnol. - Int. J. Lim. 55: 12 